\title{
Experience of general practice by a psychiatric trainee
}

\author{
Simon BaLmer, Registrar In Psychiatry, Bootham Park Hospital, Bootham, \\ York YO3 7BY
}

As I approach the end of an innovative attachment I thought it might be useful to put a few thoughts on paper, not only to thank those who set up the scheme but in the hope that other psychiatric training schemes might replicate the opportunity.

\section{The scheme}

The job I am currently doing is split between working as a psychiatry registrar in the Friarage Hospital, Northallerton and being attached to the East Road GP Surgery, also in the town. The scheme aimed to give psychiatric trainees an idea of what general practitioners do, to see what patients consult them, and also to broaden clinical skills

Northallerton Health Authority is a large rural health district covering some 1500 square miles, including the Yorkshire Dales (Simpson, 1989). There are traditionally good links between GPs and the Department of Psychiatry. The GP practice itself is one of two large practices in Northallerton and is staffed by four full-time partners, two part-time partners and a 'normal' GP trainee.

\section{The work}

The initial problem was setting a timetable. The split between psychiatry and general practice left three surgeries a week plus attendance at the GP vocational training scheme afternoon. For the first couple of weeks I sat in with my trainer observing how to conduct a six minute consultation and, more importantly, picking up clinical pointers on what to do when somebody presents with a sore throat, cough, a discharge or indeed any of a long list of complaints which four years as a psychiatric trainee had diverted to the forgotten recesses of my mind. I then did surgeries on my own, starting with 15 minute consultations and, moving to ten minute ones. I regularly accompanied my trainer on home visits. On-call commitments to the hospital as part of the other side of the job precluded my participation in the GP on-call rota.

\section{Supervision}

Supervision and feedback were good. I discussed all cases with my trainer and could bring problems to him; commenting on my videotaped consultations proved to be a useful experience. My most valuable training though was in informal discussion driving between visits with my trainer, discussing patient management, GP life and his love of Alfa Romeos. The practice had regular management meetings, exposing my previous lack of training to such matters.

\section{The experience}

I approached the post with great trepidation since I had done no general medical jobs since house year, approximately five years previously. I was interested to see what general practice was like and observe what GPs actually did during the day. I was curious to see if they were particularly psychologically minded, managed psychiatric problems well and what contacts they really did have with the Psychiatric Department, and indeed what they thought about the local Psychiatric Department and psychiatry in general.

The Royal College of Psychiatrists was uncertain that I would be exposed to adequate psychopathology. I therefore kept a logbook. Although I saw numerous people with upper respiratory tract infections, there was a large spread of psychological problems to manage, including considerable numbers of people suffering from anxiety, depression, family problems as well as stress reactions. I felt that $35 \%$ of consultations were primarily for psychological disorders. I enjoyed the job and gained a lot from it. The diversity was startling and I never knew who would wander through the door next, what their presenting complaint might be and what other underlying difficulties I might discover. This was the greatest challenge and I tried to talk to my GP colleagues who saw these patients subsequently to clarify and validate my personal hypotheses.

The job convinced me that a sound knowledge of peoples' background is essential in both primary care and psychiatry. It also helps to have been in practice for a while. Patients then start to trust you and comply with advice.

I enjoyed tackling problems far removed from the presenting complaint. For example, one man comes to mind who presented with a sore throat but 20 minutes later we were still discussing his reaction to the death of a close relative. 


\section{Colleagues}

The GPs were open, friendly and welcomed me. They all seemed to have an interest in psychiatry. Occasionally it proved difficult when I felt my trainer was over-enthusiastic in his encouragement to search for psychological problems behind the presentation. My feeling was that at least some people with respiratory tract infections came because of the physical discomfort caused rather than a "hidden psychiatric agenda'.

\section{The difficulties}

The split nature of the post made things difficult at times. Sometimes I felt that I wore two hats. It was especially difficult seeing patients whom I had also advised as a psychiatrist in hospital. From the start the GPs established that I was not a psychiatric adviser to the practice and saw a standard caseload.

On visits I was introduced as "the doctor who is with us for six months" and only on special occasions as "Dr Balmer, he specialises in psychiatry you know". There were few adverse reactions to my presence, and indeed most of the patients seemed somewhat "chuffed" by this.

My rustiness and ignorance on general medical matters worried me considerably before the placement. However, this did not prove to be as big a problem as I feared. I found it easy to ask for advice. Initially receptionist staff would not push children my way as I had expressed concern at handling such patients. However, this changed as my confidence grew and, as far as I know, the mortality rate in Northallerton has not increased because of this.

\section{Comment}

I felt I gained good insight into the mechanism of general practice and thoroughly enjoyed the time. I was impressed by the experience, empathy and psychological mindedness of the general practitioners and felt more able to manage my time when seeing patients. It is amazing just what information can be obtained and how much decided in a short period. I think Northallerton is probably unusual in the strength of its links with the community, general practice and the district general hospital. Hopefully the continuation of this post on a psychiatry training scheme will help these links improve further. At the very least I think I have shattered the illusion that all psychiatrists have zany ties, haircuts and accents.

\section{Acknowledgements}

Many thanks go to Dr Gareth Vincenti, Consultant Psychiatrist; Dr Chris Oates, General Practice Trainer; the General Practitioners and Staff at the and to Dr Gopalaswamy, Clinical Tutor.

\section{References}

Simpson, C. J. (1989) All creatures great and small. Psychiatric Bulletin, 13, 605-606. 